i-DUST 2010, $03001(2011)$

DOI: 10.1051 idust/201103001

(C) Owned by the authors, published by EDP Sciences, 2011

\title{
Meuse/Haute-Marne underground research center - Technologies and techniques for studying gas flow and thermal properties of an indurated clay-rock
}

\author{
J. Delay ${ }^{\mathrm{a}}$, N. Conil, and R. de La Vaissière \\ Andra, Direction Scientifique, Centre de Meuse-Haute-Marne, RD960, BP. 9, \\ 55290 Bure, France
}

\begin{abstract}
The Meuse/Haute-Marne Underground Research Laboratory (URL) is the main installation of the Meuse/Haute-Marne Center. Its research program is dedicated to preparing the construction and operation of a deep geological disposal facility for high-level and intermediate-level long-lived radioactive waste (HL, IL-LLW). The URL consists of two shafts giving access to the drift networks where the physical and chemical containment properties of a 160-million-year old clay layer are under study. This paper presents technologies and techniques implemented in the framework of the gas flow and thermal properties experiments carried out on the Callovo-Oxfordian argillaceous rock formation. Since gases will be produced by the deterioration of the disposal components (packages, packaging components, metallic construction material), knowledge of their production and migration mechanisms in the rock formation (PGZ experiment) are of particular significance for the operation safety and, in the long term, for the safety of the installation itself. In addition, some heat generating packages will entail significant evolutions of the natural constraints at close- and long-range from the packages. Knowledge of the thermo-hydro-mechanical behaviour of the rock formation (TED experiment) is supporting the architecture design of the underground installations and their developments in the course of operation.
\end{abstract}

\section{INTRODUCTION}

Andra is a French industrial and commercial public body established by the December 30, 1991 Waste Act. Its role was completed by the June 28, 2006 Planning Act concerning the sustainable management of radioactive materials and waste. It is supervised by the Ministry for energy, the environment and research, and is responsible for the sustainable management of all French radioactive waste.

The Meuse/Haute-Marne Underground Research Laboratory is located on the eastern boundary of the Paris Basin, in the Callovo-Oxfordian clay rock formation. The URL was built in the framework of Andra's research program aimed at determining the feasibility of a reversible deep geological disposal of high-level and intermediate-level long-lived radioactive waste (HL, IL-LLW). Its underground drifts are used to study a 160-million-year old clay layer and characterize the confinement properties of this argillaceous rock [1].

ae-mail: jacques.delay@andra.fr

This is an Open Access article distributed under the terms of the Creative Commons Attribution-Noncommercial License 3.0, which permits unrestricted use, distribution, and reproduction in any noncommercial medium, provided the original work is properly cited. 


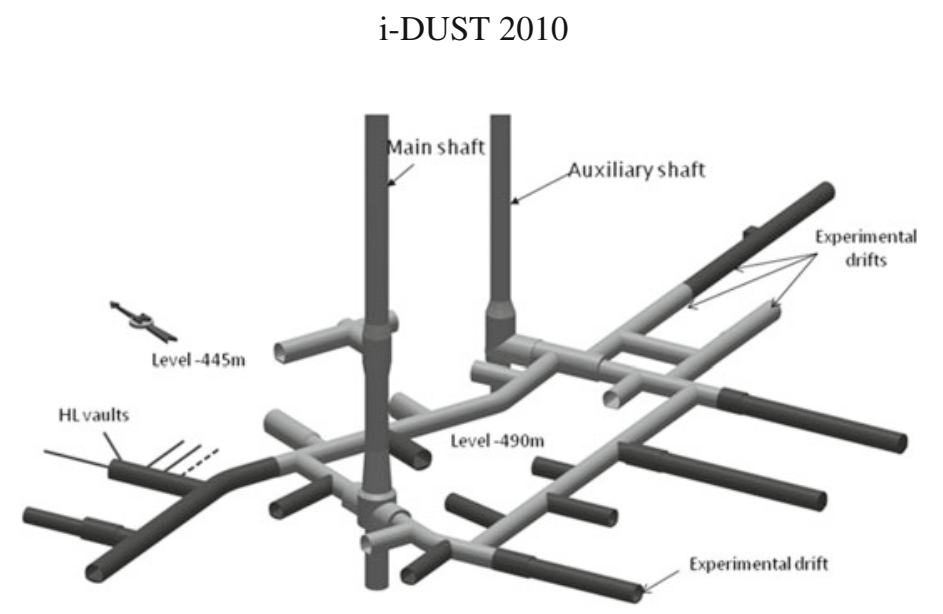

Figure 1. Lay-out of the underground drifts.

\section{DESCRIPTION OF THE URL}

The underground installations consist of two shafts and drift networks (Figure 1). The main shaft, $5 \mathrm{~m}$ in diameter after lining, gives access to a 445 meter-deep drift network and to the $490 \mathrm{~m}$-deep main drift network. The functionalities of this shaft are as follows:

- Access for the personnel,

- Transportation of the equipment,

- Clearing of the dump material,

- Ventilation system air inlet.

The auxiliary shaft, $4 \mathrm{~m}$ in diameter after lining, is also serviced by two elevators of identical size, able to descend below the shaft station to make way for heavy-load or large-bulk carrying machines. The auxiliary shaft acts as an emergency exit. It also ensures the ventilation system air circulation and, to this effect, it comprises at surface level an extraction room and a chimney.

The T-shaped drift network at $-445 \mathrm{~m}$ is 45 meter-long. This experimental zone has been equipped to monitor the reaction of the rock mass during shaft sinking from $-445 \mathrm{~m}$ to $-465 \mathrm{~m}$. The drifts are between $17 \mathrm{~m}^{2}$ and $20 \mathrm{~m}^{2}$ in section. The main network of experimental and technical drifts is located at $-490 \mathrm{~m}$. In July 2010, this network was 1000 meter-long, out of which 300 meters are dedicated to experiments. The orientation of the scientific drifts has been determined with respect to the in-situ stress field.

\section{PGZ EXPERIMENT}

\subsection{Objectives}

In the conceptual representation of gas flows in clays, it is considered that a mode of transfer, called dilation, exists above the fracturing pressure. This transfer mode (dilation), previously identified in bentonite, is associated with the opening of pathways for localized percolations.

Gas, released by disposal packages and flowing in the rock, is classically described by four mechanisms i) advective-diffusive transport of gas dissolved in the porewater, ii) visco-capillary twophase flow, iii) dilatancy-controlled gas flow and iv) gas transport in macroscopic tensile fractures. An in situ gas experiment in the French Underground Research Laboratory (URL) is dedicated to the observation of these four mechanisms. This experiment called PGZ1 (Perturbation induced by gas) was set-up in summer 2009. 


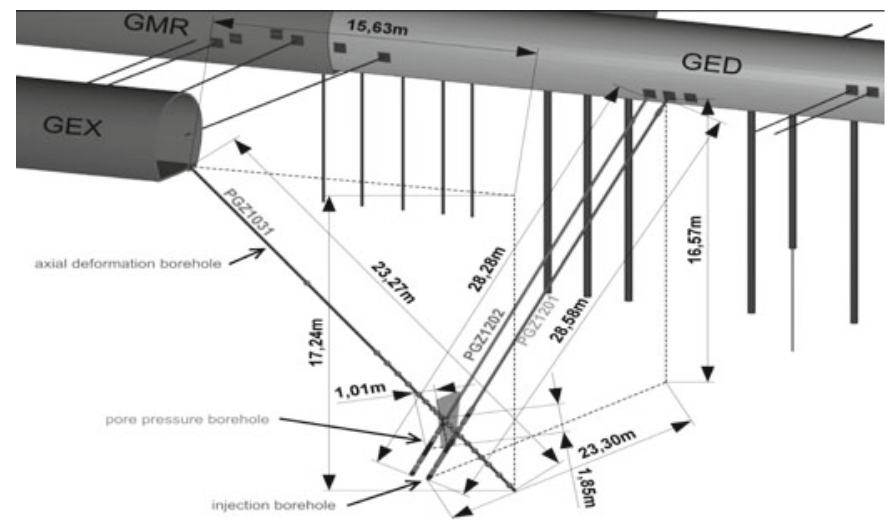

Figure 2. Set up of the PGZ1 experiment.

The aim of a PGZ1 experiment is to use gas-injection tests to characterize gas transfer properties in a formation with the view to confirm the parameters and limits of the traditional biphasic model and provide additional support for describing gas transfer, such as:

- Assessing the pressure at which gas can enter the undisturbed argillaceous rock,

- Assessing the threshold gas pressure above which pathway dilation occurs,

- Positioning this threshold with respect to the fracturing pressure,

- Characterizing the gas generated joint network (reversible or not).

\subsection{Concept}

\subsubsection{Scoping calculation}

The location of the boreholes and intervals were defined by scoping calculations prior to drilling. Numerical models were used to investigate the relevant phenomena associated with two-phase flow, taking into account the coupled HM processes associated with dilation and fracturing. The numerical codes include the two-phase flow simulator TOUGH2 [2] and the coupled two-phase geomechanical code GEOSIM (TAURUS Reservoir simulation Ltd.).

\subsubsection{Experimental set-up}

The experimental layout consists of three boreholes (Figure 2). Two boreholes drilled from GED drift PGZ1201 and PGZ1202, 28.59 meter and 28.28 meter-long respectively, are equipped with a triple packer system to monitor water/gas pressure. They are $1 \mathrm{~m}$ distant from one another, parallel and inclined at $35^{\circ}$ versus horizontal. These boreholes are oriented parallel to the main maximum stress. PGZ1031 (23.27 meter-long), drilled from the GEX drift, is equipped with a multiple magnetic extensometers probe (MagX system $\left.{ }^{\circledR}\right)$ for observation of the axial deformation. PGZ1031 is also inclined at $48^{\circ}$ versus horizontal. This borehole crosses vertically above PGZ1201 at a distance of 2.2 meters.

Significant uncertainties remain concerning the predicted orientation of the fracture. Therefore, following the gas-fracturing stage, a final borehole (PGZ1032) designed to measure interstitial pressures, will be drilled to assess the fracture permeability to water and gas. 


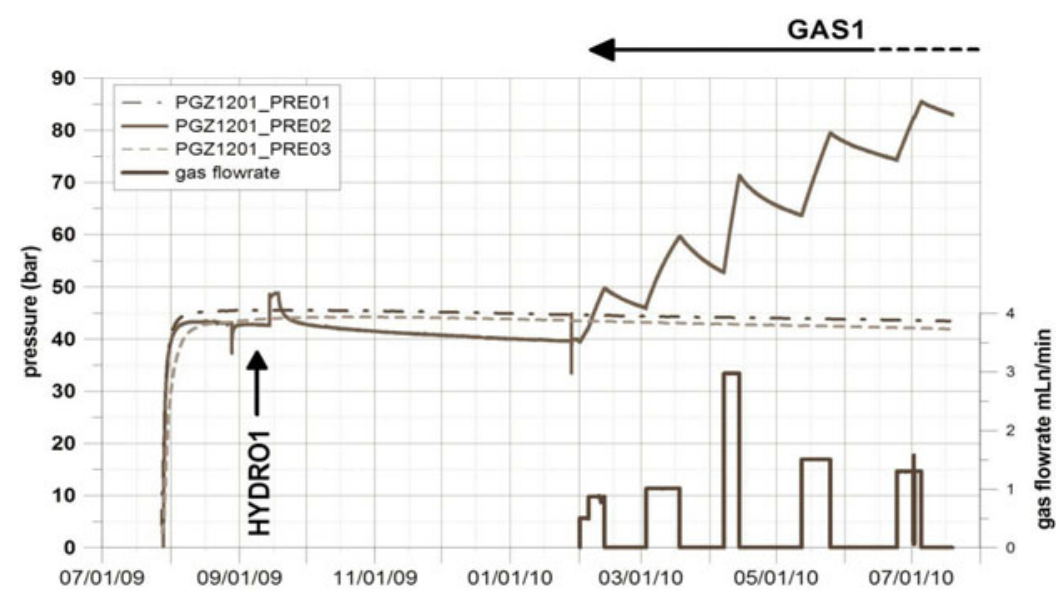

Figure 3. Monitoring of borehole PGZ1201 measurements.

\subsubsection{Tests sequence}

The entire test sequence will take place in interval 2 of PGZ1201. The first test phase (HYDRO1), will comprise a pulse test and a constant pressure test. Following the recovery period, the water will be replaced with gas (nitrogen) at equilibrium conditions (formation pressure). The second test phase (GAS1) will consist of a series of constant gas injection flow rates separated by recovery periods. The maximum gas pressure will remain below fracturing pressure (close to $12.3 \mathrm{MPa}$ ), but it should reach dilation conditions. The third test phase (HYDRO2) will be performed at the end of GAS1, after the gas is flushed, again using synthetic water. The aim of HYDRO2 is to identify any possible change in the formation permeability following the gas tests performed under expected dilation conditions (GAS1). The aim of the fourth test phase (GAS2), similar to GAS1, is to create a macroscopic tensile fracture. The detailed test design of GAS2 will depend on the results of GAS1. The created fracture is expected to appear in PGZ1031. A fifth test phase (HYDRO3), also using synthetic water, will be performed at the end of GAS2 to characterize the geometrical and hydraulic properties of the newly created fracture.

The whole experiment, from HYDRO1 to HYDRO3, is expected to last about 2 years.

Comparison of the results obtained from HYDRO1 to HYDRO3 will provide information on the evolution of the system induced by gas injection. An additional borehole, PGZ1032, almost parallel to PGZ1031, will be drilled from the GEX drift to reach the gas generated fracture. This borehole will be instrumented by a triple packer system with one test interval located on the fracture. Some gas and hydro tests will be performed in PGZ1201 to evaluate the permeability of the fracture. The subsequent sealing/healing of the fracture will also be investigated.

\subsubsection{Modeling activities}

Extensive modeling is planned to interpret and analyze all the results obtained from the PGZ1 experiment. To this effect, several groups will be involved in computations in the framework of the FORGE project (Fate of Repository Gases). This European project, initiated in 2009, is specifically designed to address the key research issues associated with the generation and movement of repository gases.

\subsection{Measurements}

Figure 3 shows the flow and pressure of the gas injected in borehole PGZ1201. 
J. Delay et al.: Meuse/Haute-Marne underground research center

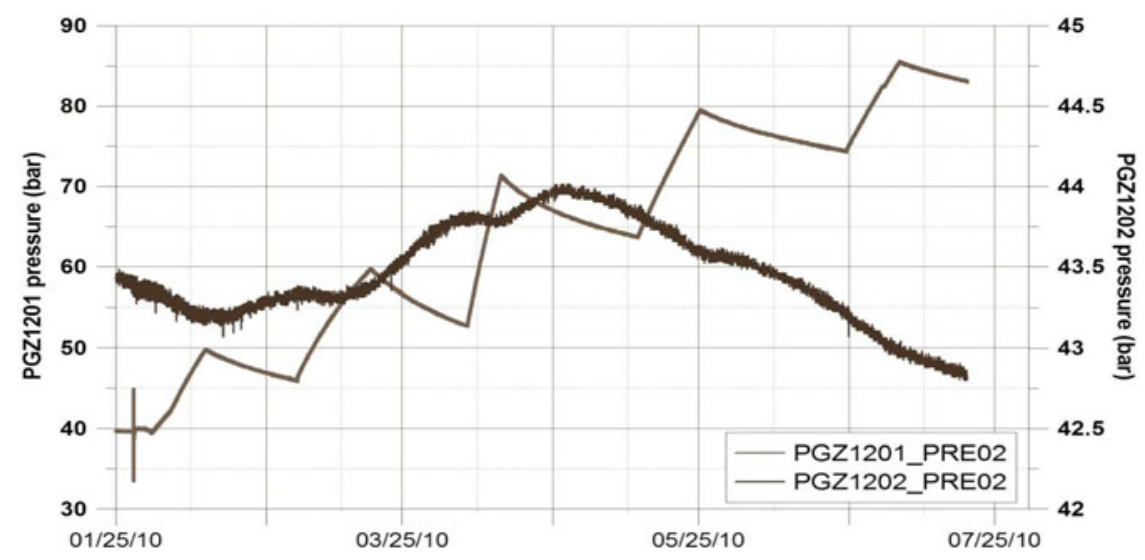

Figure 4. Interstitial pressure measured at interval 2 of boreholes PGZ1201 and PGZ1202 (phase GAS1).

The pressures measured in borehole PGZ1201 show a drop in interstitial pressure following a pressure equilibrium phase. This drop is accounted for by the drainage of borehole PGZ1031 passing at a minimum distance of $1.2 \mathrm{~m}$ from interval 2 (PGZ1201_PRE02).

The HYDRO1 hydraulic test phase was carried out in September 2009 in interval 2 of borehole PGZ1201. Both hydraulic tests were interpreted using a composite radial model with a $2.610^{-13} \mathrm{~m} / \mathrm{s}$ permeability value for the external zone, and a $6.410^{-11} \mathrm{~m} / \mathrm{s}$ internal permeability value. The discontinuity radius between the internal and external zones is very close to the borehole wall $(2 \mathrm{~mm})$. The permeability value of the external zone is consistent with the permeability of the intact rock. These results show that gas injection in this interval will help identify the intact rock. End of January 2010, the water in interval 2 was replaced by gas at an equivalent pressure and phase GAS1 started on 1 February 2010 (Figure 3).

Figure 4 shows the hydraulic interference observed at the level of interval 2 of borehole PGZ1202, located at about $95 \mathrm{~cm}$ from the gas injection interval. On the reverse, on figure 3, both intervals adjacent to the PGZ1201 injection interval show no hydraulic interference. These observations indicate that the injected gas gradually penetrates into the rock and does not pass along the borehole via the interfaces.

In interval 2 of PGZ1202 (PGZ1202_PRE02), the last two gas injection steps induced a low response in terms of amplitude with respect to the three first steps, possibly owing to the fact that the two latter flow steps are significantly weaker than the third one (Figure 3). Not to mention the drainage of borehole PGZ1031 and the previous gas injection steps.

\subsection{Preliminary results}

These first measurements confirm that the gas entry pressure into the intact rock is close to that measured on samples. However, according to the ongoing preliminary analyses, the formation parameters might evolve in the course of phase GAS1. The pressure threshold of the last phase GAS1 step will be 100 bars, i.e, 23 bars below the minimum constraint value.

\section{TED EXPERIMENT}

\subsection{Objectives}

TED is a thermal experiment initiated in July 2008 in the URL drifts. This experiment follows a first TER [3] experiment carried out between 2005 and 2009. Its aim is to confirm and complete the results, and reduce the uncertainties, regarding the THM parameters. This experiment involves three heating probes. 
The objectives of this experiment are as follows:

- Determine the thermal properties of the undamaged rock,

- Study the impact of the superimposition of thermal fields in the rock formation and verify the amplitude of the overpressures induced by heat,

- Complete the acquired knowledge on the Thermo-Hydro-Mechanical (THM) behaviour of the argillite and quantify the THM parameters based on in situ tests,

- Verify the relevance of the THM coupling parameters measured on samples,

- Study the possible occurrence mechanisms of a fractured zone in the vicinity of a heated borehole during the thermal phase.

A measurement program on samples and numerical simulations are carried out concurrently to the in situ measurements.

\subsection{TED experimental design}

The experimental design is based on the feedback of the previous thermal experiment (TER) and the results of the associated thermal and thermo-hydromechanical numerical computations.

- The heated boreholes are lined in order to protect the probe from breakouts.

- The presence of formation water has been noticed in two TER experimental lined boreholes. In order to optimize the quality of the measurements and avoid drainage of the studied zone, all the lined boreholes of the TED experiment are designed to sustain a 5 MPa hydrostatic pressure.

- Several months into the TER experiment, about 30\% of the Pt100 type temperature probes were affected (offset, noise, drift). In order to restrict the loss of data, "duplex" sensors (two encapsulated Pt100 sensors in the same packaging) were used in the surrounding boreholes and heated boreholes.

- The analysis and numerical computations carried out following the TER experiment highlighted some discrepancies between the displayed locations of the captors and their behaviour [4,5]. This seems to be accounted for by errors in the locations of the sensors in the rock formation. In the case of the TED experiment, the precise location at $\pm 1 \mathrm{~cm}$ (uncertainty of the topographical measurements) of the set of sensors of each borehole has been measured using a topographical target attached to the laboratory topographical localization system.

- Computations carried out for the TER experiment highlighted the influence of the seasonal temperature variations in the GED drift up to $7 \mathrm{~m}$ from the wall $[4,5]$. Accordingly, the heating probes of the TED experiment were placed $12 \mathrm{~m}$ from the drift wall. In addition, sensors were placed at the surface of drift GED, $30 \mathrm{~cm}$ from the drift wall, at the level of the TED experiment, in order to measure accurately the seasonal temperature variations.

To characterize the hydraulic damage caused by heating, permeability measurements were carried out in the pressure boreholes before heating. Additional measurements will be carried out before each heating step and after the experiment is completed.

\subsection{Concept of the TED experiment}

The TED experiment involves:

- 3 heated boreholes,

- 12 interstitial pressure measurement boreholes,

- 9 temperature measurement boreholes (Figure 5),

- 2 deformation measurement boreholes,

- 8 wall temperature sensors.

Two types of instrumentation are used for pressure measurements: monopackers and multipackers. Both multipackers are located in order to measure the pressure gradient between the drift wall and a distance of $20 \mathrm{~m}$, in a zone non-impacted by heating. Practically all the monopackers are located in order to measure the pressure $14 \mathrm{~m}$ from the drift wall in zones parallel to the heating probes, ranging between 


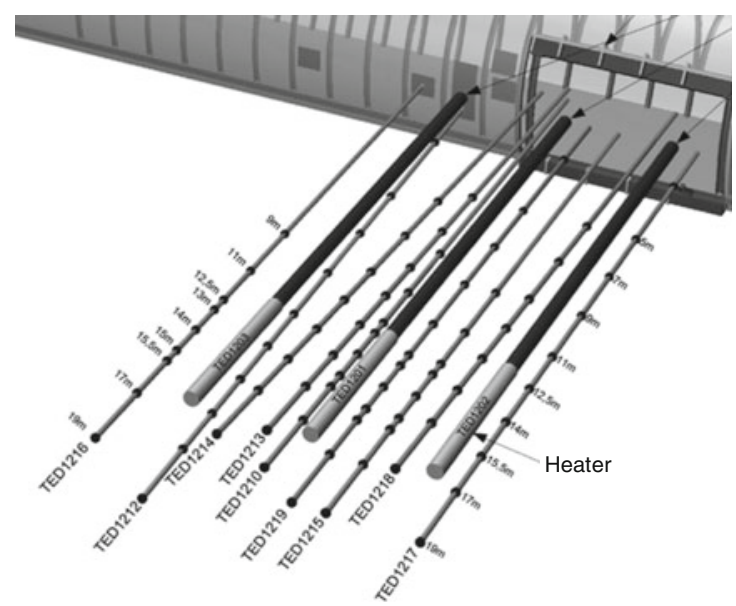

Figure 5. Locations of the temperature boreholes.

$10 \mathrm{~cm}$ and several meters. In addition, two boreholes equipped with monopackers are used to measure pressure at $10.5 \mathrm{~m}$ and $20 \mathrm{~m}$ distance from the drift wall in the heated zone.

Each peripheral temperature borehole comprises, on average, 10 Pt100 probes.

Design calculations have shown that, once the three probes were in operation, a thermal pressure of about $600 \mathrm{~W}$ had to be applied to obtain a temperature close to $90^{\circ} \mathrm{C}$ at the tube wall. Two 4-months intermediate steps will be applied at $25 \%$ and $50 \%$, i.e., $150 \mathrm{~W}$ and $300 \mathrm{~W}$, respectively, prior to the final thermal load. Heating has started with the central heating probe, after a year, the same thermal load will be applied to the two peripheral heating probes.

\subsection{Preliminary results}

The two first heating steps, at $150 \mathrm{~W}$ and $300 \mathrm{~W}$, started in the central heated borehole on 25 January 2010 and 25 May 2010, respectively.

In all, 3 measurement sections are located on the heated area (S1, S2 and S3) between $12 \mathrm{~m}$ and $16 \mathrm{~m}$ from the drift wall, and 5 sections on the non-heated area between 0 and $12 \mathrm{~m}$. Measurements, recorded since the installation of the probe on four sections of the heated borehole, are shown in Figure 6.

Temperatures have been recorded continuously in the heated boreholes and peripheral boreholes.

Figure 7 shows the evolution of temperatures in a borehole $130 \mathrm{~cm}$ from the de heating probe. For both steps, the beginning of each heating phase is clearly visible.

At the present stage of the experiment, these measurements are consistent with the predictive calculations. These calculations were carried out with the thermal parameters based on the results of the TER experiment:

$$
\begin{aligned}
& \lambda_{/ /}=2 \mathrm{~W} / \mathrm{m} / \mathrm{K} \\
& \lambda_{\perp}=1,3 \mathrm{~W} / \mathrm{m} / \mathrm{K} \\
& \rho=2390 \mathrm{~kg} / \mathrm{m}^{3} \\
& \mathrm{C}_{\mathrm{p}}=1005 \mathrm{~J} / \mathrm{kg} / \mathrm{K} .
\end{aligned}
$$

Shortly, when the two other heating probes are in operation, it will be possible to assess the influence of the superimposition of the thermal fields on the pressures and temperatures of the rock formation. 


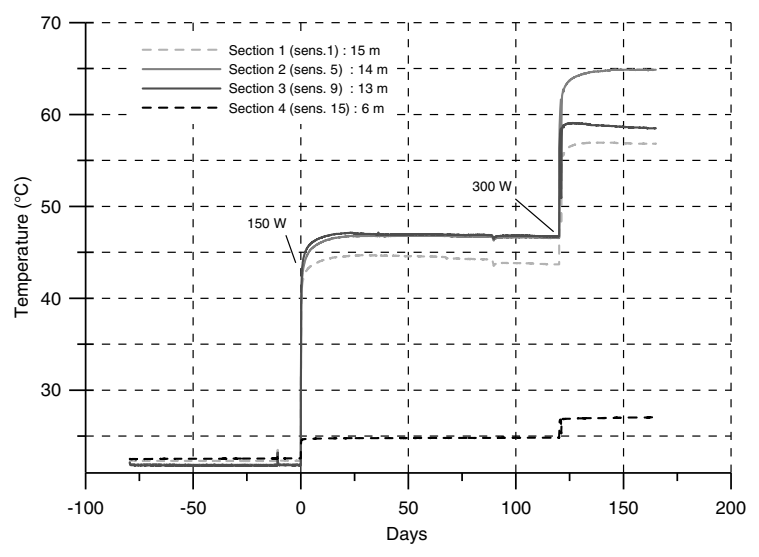

Figure 6. Evolution of the temperatures in the heated borehole TED1201.

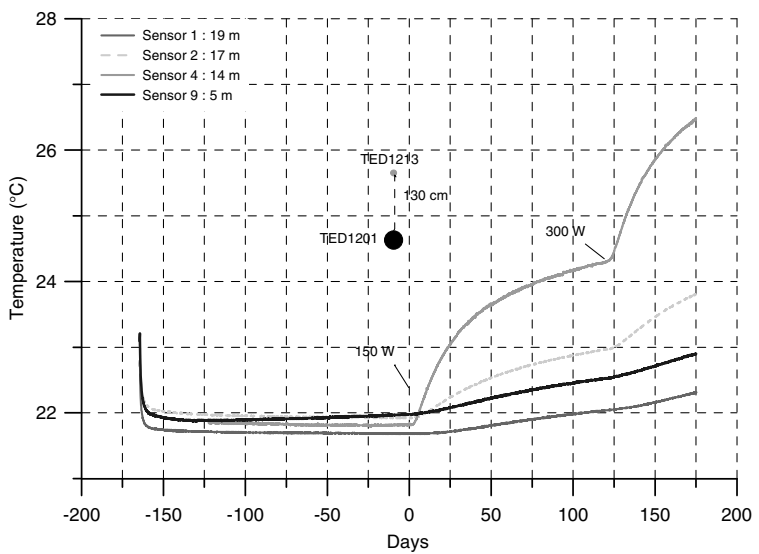

Figure 7. Evolution of the temperatures in borehole TED1213.

\section{CONCLUSION}

The main achievements of the studies and works carried out so far in the Meuse/Haute-Marne URL are the detailed characterization of the confining properties of the Callovo-Oxfordian argillaceous rocks and the understanding of the behaviour of the various disposal elements, with more specifically, the fractured zones occurrence mechanisms and means for limiting their hydraulic effect.

The new law on the management of radioactive waste $\left(28^{\text {th }}\right.$ June 2006$)$ opened a new ten-year research period with the view to establishing the authorization and construction of a disposal facility [6].

Future works fall under a scientific program aimed at providing the scientific elements supporting the choice of design options for the disposal facility and dedicated to the understanding of specific issues (gas, thermal hydro-couplings)

The scientific program consists of:

- New experiments on the physicochemical interactions of the disposal materials (glass, iron, concrete, bentonite).

- New experiments on the circulation of gases in the geological formation, and thermo-hydromechanical experiments. 
J. Delay et al.: Meuse/Haute-Marne underground research center

\section{References}

[1] J. Delay, A. Vinsot, J.M. Krieguer, et al. Physics and Chemistry of the Earth, 32: 2-18 (2007)

[2] K. Pruess, C. Oldenburg and G. Moridis, Report LBNL-43134, Berkeley, CA (1999)

[3] Y. Wileveau and K. Su, Proc. $3^{\text {rd }}$ Int. Meeting on Clays in Natural \& Engineered Barriers for Radioactive Waste Confinement, Lille, France, September 17-20 (2007)

[4] M. Filippi, G. Armand, V. Blin, S. Dewonck, J.M. Martinez, J. Radwan, Clays in Natural \& Engineered Barriers for Radioactive Waste Confinement, Nantes, France, $29^{\text {th }}$ March- ${ }^{\text {st }}$ April 2010 (2010), Nantes

[5] B. Garitte, J. Vaunat, A. Gens, G. Armand, Clays in Natural \& Engineered Barriers for Radioactive Waste Confinement, Nantes, France, $29^{\text {th }}$ March-1 ${ }^{\text {st }}$ April 2010 (2010), Nantes

[6] J. Delay, P. Lebon, H. Rebours, Journal of Rock Mechanics and Geotechnical Engineering, 2010, 2(1), pp 52-70 